\title{
Genetic polymorphism of merozoite surface protein-1 and merozoite surface protein-2 in Plasmodium falciparum isolates from Brazzaville, Republic of Congo
}

Pembe Issamou Mayengue ${ }^{1,2}$, Mathieu Ndounga ${ }^{3}$, Freddy Vladimir Malonga ${ }^{1,2}$, Michel Bitemo ${ }^{4}$ and Francine Ntoumi ${ }^{1,2,5^{*}}$

\begin{abstract}
Background: The characterization of malaria parasite populations circulating in an area is part of site characterization, as a basis for evaluating the impact of malaria interventions on genetic diversity, parasite species, and multiplicity of infection. The present study was aimed at analysing genetic diversity of Plasmodium falciparum merozoite surface proteins 1 and 2 (MSP-1 and MSP-2) and to determine the multiplicity of infection in clinical isolates collected from children living in the Southern district of Brazzaville in the Republic of Congo.

Methods: A total of 125 isolates from patients with uncomplicated malaria attending Terinkyo and Madibou health centres were collected between January and June 2005 while evaluating the therapeutic efficacy of amodiaquineartesunate combination. DNA was extracted and $m s p-1$ and $m s p-2$ genes were genotyped using allele-specific nested-PCR.

Results: Out of 468 distinct fragments detected, 15 msp-1 and 20 msp-2 genotypes were identified. For the msp-1 gene, K1 family was the predominant allelic type carried alone or in association with RO33 and Mad20 types, whereas the 3D7 family was the most prevalent in the msp-2 gene. Overall, the mean multiplicity of infection was 2.2. Out of 125 samples, 104 (83\%) harboured more than one parasite genotype. There was no statistical significant difference in the multiplicity of infection by either sex or age of patients. However, a statistically significant correlation was found between parasite densities and the number of genotypes.

Conclusion: Polymorphism in P. falciparum clinical isolates from Brazzaville was high and mainly of multiple clones. The basis for the positive association between parasite densities and multiplicity of infection is discussed.
\end{abstract}

\section{Background}

Malaria, a disease mostly caused by Plasmodium falciparum, is a major public health problem. The global burden is estimated at 225 million malaria cases every year resulting into 781,000 deaths [1], sub-Saharan Africa being the most affected region. In the Republic of Congo, like in many other sub-Saharan African endemic countries, malaria vulnerable groups are children and pregnant women [2].

\footnotetext{
* Correspondence: fntoumi@fcrm-congo.com

'Fondation Congolaise pour la Recherche Médicale, BP 2672 Brazzaville, Republic of Congo

Full list of author information is available at the end of the article
}

Data collected from 2000 to 2003 by the University Teaching Hospital of Brazzaville during studies on chloroquine resistance showed that $22 \%$ of children deaths at pediatric health facilities were due to malaria [3]. Recent studies on anti-malarial drug resistance in Brazzaville have confirmed high level chloroquine resistance and the inefficacy of sulphadoxine-pyrimethamine and amodiaquine either singly or in combination for the treatment of uncomplicated malaria [4-6]. Consequently, in February 2006, the Republic of Congo changed its anti-malarial drug policy for treating uncomplicated malaria to artesunate-amodiaquine combination, as the first-line drug, and

\section{Ciomed Central}

(c) 2011 Mayengue et al; licensee BioMed Central Ltd. This is an Open Access article distributed under the terms of the Creative Commons Attribution License (http://creativecommons.org/licenses/by/2.0), which permits unrestricted use, distribution, and reproduction in any medium, provided the original work is properly cited. 
artemether-lumefantrine the second-line thus meeting the recommendation of the World Health Organization.

Despite policy change, there is still need to collect more data on the epidemiology of malaria in the country to facilitate the development and implementation of other malaria control interventions such as the search for alternative drugs, vaccine trials and indoor residual spraying. In this regards, characterization of malaria parasite populations circulating in an area is part of site characterization before any intervention, as a basis for evaluating the impact of the intervention on genetic diversity, parasite species, and multiplicity of infection (MOI) in the human or vector host. One of the limitations to the development of an effective malaria vaccine against $P$. falciparum is the extensive genetic diversity in parasite populations limiting the efficacy of acquired protective immunity to malaria [7]. MOI and demonstration of presence of parasite in blood are among the most useful indicators of clinical disease [8-11]. In the human host, MOI is defined as the mean number of detected $P$. falciparum genotypes per infected individual.

Asexual blood stages antigens, such as merozoite surface protein-1 (MSP-1) and merozoite surface protein-2 (MSP-2) are considered prime candidates for the development of malaria vaccine and are also suitable markers for the identification of genetically distinct $P$. falciparum parasite sub-populations [12]. Polymorphism in $m s p-1$ and $m s p-2$ has been reported in several parts of world including in Central Africa [13-15]. However, there is limited data on the genetic diversity among P. falciparum populations from the Republic of Congo.

Molecular studies to identify P. falciparum genes mutations associated with anti-malarial drugs resistance, such as those found in P. falciparum chloroquine resistance transporter, dihydrofolatereductase, dihydropteroate synthase have been conducted in the Republic of Congo since 2003, before introducing artemisinin-based combination treatment (ACT) in $2006[5,16,17]$. Base on the literature, only one publication has reported the genetic diversity of $P$. falciparum infections and MOI in a group of children with uncomplicated malaria in Brazzaville [5]. Following massive deployment of insecticide treated nets and free treatment with ACT for malaria in the country, it is important to evaluate the genetic profile of malaria strains before and during these effective interventions.

The present characterized allelic polymorphism of $m s p-1$ and $m s p-2$ and determined the multiplicity of infection in clinical $P$. falciparum isolates collected from children living in the southern district of Brazzaville, the capital of the Republic of Congo. The Ministry of Public Health of the Republic of Congo approved the study ethically and scientifically.

\section{Methods}

\section{Study area}

The study materials were collected from patients attending Centre de Santé Intégré (CSI) in Terinkyo and Madibou hospitals, located in the southern part of Brazzaville. This urban area has stable and highly endemic malaria with perennial transmission [18] with an entomological inoculation rate (EIR) of 22.5 infective bites/person/year was reported [19]. Malaria infection is primarily due to P. falciparum.

\section{Study population and blood samples collection}

A total of 125 P. falciparum infected blood used in this study were collected from children and adults presenting to the two health centres and enrolled into the study for evaluating the therapeutic efficacy of artesunate-amodiaquine combination (Dr. Ndounga, unpublished data) from February to June 2005. The inclusion criteria of participants were: auxiliary temperature $\geq 37.5^{\circ} \mathrm{C}$ measured with an electronic thermometer, malaria parasite ( $P$. falciparum) in the thick blood smears ( $\geq 800$ parasites $/ \mu \mathrm{L}$ ), no symptoms of severe malaria or febrile conditions caused by other diseases. Informed consent was obtained from adult patients and from parents/guardians for the children. Additionally, at inclusion into the study and before treatment, three drops of blood from each patient were blotted on to $3 \mathrm{MM}$ Whatman filter paper, dried and stored in individual sealed envelopes until used for DNA extraction.

\section{Extraction of parasite DNA}

Genomic DNA was extracted from blood samples collected on filter paper using QiaAmp DNA mini kit (Qiagen, Hilden, Germany) according to the manufacturer's instruction. Then, the DNA was recovered in $100 \mu \mathrm{l}$ of elution buffer from the kit. All parasites DNA extracted were stored at $-20^{\circ} \mathrm{C}$ until use.

\section{Allelic typing of $P$. falciparum msp-1 and $m s p-2$ genes}

All samples were genotyped for $P$. falciparum using the nested polymerase chain reactions (PCRs) technique. The highly polymorphic loci, $m s p-1$ block 2 and $m s p-2$ central region were used as markers for this genotyping as described previously [11-13]. The initial amplifications were followed by individual nested PCR reactions using specific primers for K1, MAD20, and RO33 allelic families of $m s p-1$, and for FC27 and 3D7 allelic families of $m s p-2$. Allelic specific positive controls and DNA free negative controls were included in each set of reaction. Five microliters of each of the PCR products were loaded on $2 \%$ agarose gel, stained with the Syber Green, separated by electrophoresis and visualized under UV trans-illumination. Individual alleles were identified by fragment length 
and by the corresponding allele-specific primers used and the size of the PCR products were estimated using a 100 bp DNA ladder marker (Invitrogen, Karlsruhe, Germany). The size polymorphism in each allelic family was analysed; assuming that one band represented one amplified PCR fragment derived from a single copy of $P$. falciparum $m s p$ 1 or $m s p-2$ genes. Alleles in each family were considered the same if fragment size were within $20 \mathrm{bp}$ interval. The minimum number of genotypes per isolate was estimated to be the highest number of fragments identified for either msp-1 or msp- 2 .

\section{Malaria species genotyping}

To confirm that all study participants were infected with only $P$. falciparum, all samples were subjected to Plasmodium species genotyping as described elsewhere [20]. At the second PCR round, only Plasmodium malariae and Plasmodium ovale species were investigated; $P$. falciparum being already done by $m s p-1$ and $m s p-2$ genotyping. The PCR products were loaded on $2 \%$ agarose gels and visualized under UV trans-illumination. The DNA positive controls for P. malariae and P. ovale as well as DNA free negative controls were included in each set of reaction.

\section{Data and statistical analysis}

The $m s p-1$ and $m s p-2$ allele frequency was calculated as the proportion of allele found for the allelic family out of the alleles detected in isolates. The multiplicity of infection was defined as the minimum number of $P$. falciparum genotypes per infected subject and estimated by dividing the number of amplified PCR fragments reflecting parasite genotypes by the number of positive samples. The chi-square test was used to compare proportions. Spearman's rank correlation coefficients were calculated to assess association between MOI and geometric mean parasite densities and age. Statistical significance was defined as $P$ values $<0.05$.

\section{Results}

\section{Characteristics of patients and parasitaemia}

A total of 125 patients with clinical symptoms of malaria and microscopically confirmed P. falciparum infection were enrolled in the study. Sixty-seven and 48 were children aged between seven months to five years of age, and between six to 15 years of age, respectively; ten patients were more than 16 years old. Sixty-eight patients were males and 57 were females.

The geometric mean parasite density was 62,170 parasites/ $\mu$ l of blood with the range of $830-914,000$ parasites/ $\mu \mathrm{l}$ (Table 1).

\section{Plasmodium species}

Isolates from 125 patients were PCR-typed for speciation and all were confirmed to contain P. falciparum. Of these,
Table 1 Characteristics of individuals with uncomplicated P.falciparum malaria from Brazzaville, Republic of Congo

\begin{tabular}{lcc}
\hline Characteristics of patients & No. & Values \\
\hline No. of Male/Female & 125 & $68 / 57$ \\
Mean age (years) & 125 & $8(0.7-54)$ \\
Mean parasite density (parasites/ $\mu$ ) & 125 & $62,170(830-914,000)$ \\
Multiplicity of P. falciparum infection & 125 & 2.2 \\
Polyclonal infections (\%) & 104 & 83 \\
\hline
\end{tabular}

two isolates were mixed infections of $P$. falciparum/ P. malariae and P. falciparum/P. ovale.

Allelic polymorphism of $P$. falciparum ( $m s p-1$ and $m s p-2$ ) The parasite DNA from all 125 P. falciparum isolates were analysed for $m s p-1$ and $m s p-2$ genes, whereby only one isolate did not amplify for $m s p-1$ gene. The efficiency of $m s p-1$ and $m s p-2$ genes amplification reactions with family-specific primers was $100 \%$ and $95 \%$, respectively. A total of 468 distinct fragments were detected, out of which, $15 m s p-1$ and $20 m s p-2$ different alleles were identified. Within the $m s p-1$ gene (Figure 1), eight and six alleles belonged to K1 (48\% of overall detected $m s p-1$ alleles) and Mad20 (29\%) families, respectively. The RO33 (23\%) family did not show any polymorphism, with only one variant (180 bp) detected. The K1 family was the predominant allelic type carried alone $(23.4 \%)$ or in mixed infection with RO33 (17\%) and Mad20 (20\%) types as well as when the tree types are observed in the same isolates (Table 2).

The $m s p-2$ gene yielded 10 alleles for each family (Figure 2). The 3D7 family was more prevalent with $57 \%$ of overall detected $m s p-2$ alleles compared to $38 \%$ of FC27. Forty-four (35.5\%) of the isolates carried both $m s p-2$ allelic types. Ten genotypes (5\%) could not be assigned to any family.

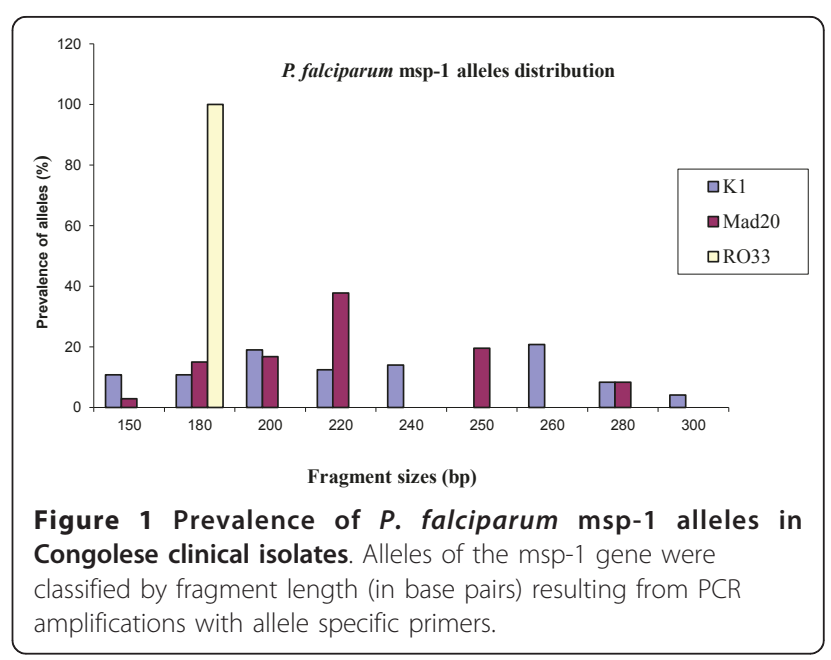


Table 2 Distribution of msp1 and msp2 detected allelic families and corresponding mean parasite densities in Congolese P.falciparum isolates

\begin{tabular}{llll}
\hline \multicolumn{4}{c}{ Mean Parasite Densities } \\
\hline MSP1 & MSP2 \\
& FC27 & 3D7 & FC27+3D7 \\
\hline K1 & 65273 & 58899 & $\mathbf{5 9 1 1 0}$ \\
Mad20 & 89818 & 76886 & $\mathbf{7 5 4 7 6}$ \\
RO33 & 60116 & 57269 & $\mathbf{6 1 4 5 4}$ \\
K1+Mad20 & $\mathbf{7 3 7 8 9}$ & $\mathbf{6 3 5 2 4}$ & $\mathbf{6 1 9 7 6}$ \\
R033+K1 & $\mathbf{6 2 5 6 1}$ & $\mathbf{5 5 7 8 8}$ & $\mathbf{5 7 1 5 1}$ \\
R033+Mad20 & $\mathbf{8 2 2 8 9}$ & $\mathbf{7 0 7 4 6}$ & $\mathbf{7 0 7 3 8}$ \\
R033+K1+Mad20 & $\mathbf{7 3 7 8 9}$ & $\mathbf{6 4 1 0 4}$ & $\mathbf{6 2 4 6 5}$
\end{tabular}

In bold are presented multiclonal infections.

Relationship between multiplicity of infection, parasite densities, age and gender

Overall, the mean multiplicity of infection was 2.2. Of 125 samples, 104 (83\%) harboured more than one parasite genotype. When considering $m s p-1$ and $m s p$ - 2 genes separately, the overall multiplicity of infection was 2 and 1.7 respectively, while eighty-nine (72\%) and 67 (54\%) of isolates carried more than one parasite genotype respectively. As presented on the Tables 2 and 3 the type of combination of multiple $m s p-1$ or $m s p-2$ alleles did not show any impact on the parasite density. Moreover, no statistical significant difference was observed in the multiplicity of infection and parasite density according to the age (Figure 3 ) and gender. However, a significant correlation was observed between mean parasite densities and the number of alleles (Spearman rank coefficient for $m s p-1=0.1784 ; \mathrm{p}=0.0474$, and Spearman rank coefficient for $m s p-2=0.1834 ; \mathrm{p}=0.0406$ ). The correlation was higher when $m s p-1$ and $m s p$ - 2 alleles are taken together (Spearman rank coefficient $=0.2508$; $\mathrm{p}=$ $0.0048)$, since the number of genotypes per isolate was calculated as the highest number of fragments for either $m s p$ 1 or $m s p$-2 (Figure 4).

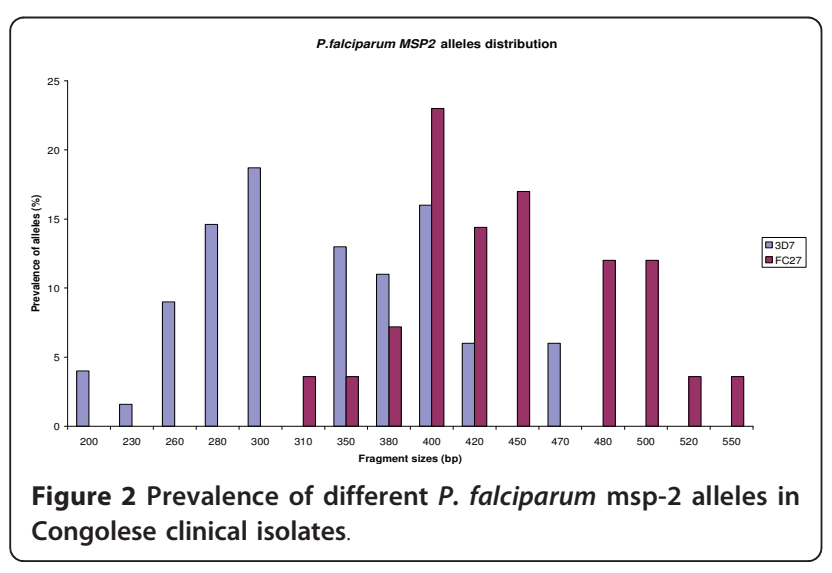

Table 3 Profile of multiple infections according to the parasite densities (P.falciparum parasites/ $\mu$ l of blood)

\begin{tabular}{cc}
\hline Multiplicity of Infection & Mean Parasite Densities \\
\hline $\mathbf{1}$ & 30,490 \\
$\mathbf{2}$ & 64,979 \\
$\mathbf{3}$ & 70,216 \\
$\mathbf{4}$ & 90,632 \\
$\mathbf{5}$ & 45,390 \\
Total & 62,170 \\
\hline
\end{tabular}

\section{Discussion}

The level of antigenic diversity of $P$. falciparum populations in an area is likely to affect acquisition of immunity to malaria [21]. Therefore, the understanding of the genetic structure of parasite population is necessary for planning of malaria control interventions.

Allelic specific P. falciparum $m s p-1$ and $m s p-2$ genotyping has shown that malaria parasite population in Brazzaville is highly diverse. However, the number of alleles may have been underestimated due to the limit of the technique. Indeed, fragments within the length interval of less than 20 bp could not clearly be distinguished. Thus, a minimum of fifteen alleles of $m s p-1$ were observed, in which, K1 allelic family was predominant, consistent with the previous study in the same locality and others studies in the central Africa subregion [5,13,22,23]. Although Mad20 family was diverse, the distribution of Mad20 alleles was almost equal to single detected RO33 allele. Regarding the $m s p-2$ locus, alleles belonging to 3D7 family were mostly detected, both in mono-infection and mixed infection with FC27 alleles. This finding differs from those of the previous study [5], where RO33 and K1 families were similarly distributed, and FC27 alleles more predominant. The difference may either be due to a small sample size in the first study or the existence of a true difference in the two study areas. Despite the fact that both studies

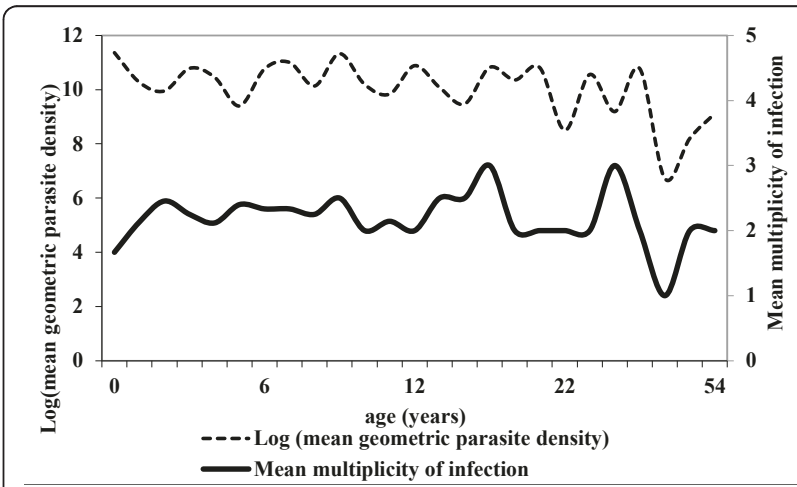

Figure 3 Relation between multiplicity of $P$. falciparum infection as well as mean geometric density with age. 


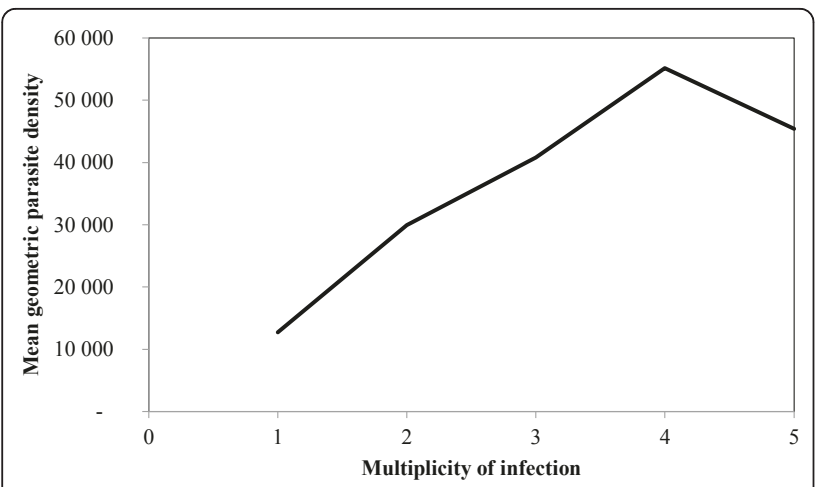

Figure 4 Relation between mean geometric parasite density and the multiplicity of $P$. falciparum infection

were done during the same time of the year, the study population for the first study conducted in 2003 lived in rural Southern areas, just after the armed conflicts in the Republic of Congo. Therefore, malaria parasite profiles found in this investigation may have not reflected the true parasite picture compared to the current study. Repeated studies are required to characterize and confirm the real genetic diversity of parasite populations in this area. Limited polymorphism in RO33 family is similar to findings in Senegal [24], Brazil [25] and in Iran [26]. Three and 4 RO33 alleles were found in Gabon [23] and Uganda [27] respectively. The current parasite profile with the predominance of K1 and 3D7 was also observed in isolates from patients with uncomplicated $P$. falciparum malaria in Gabon [22,23].

Multiple genotypes of $P$. falciparum infections were detected in $83 \%$ of Congolese isolates with an overall mean multiplicity of infection of 2.2 (with 2 and 1.7 in $m s p-1$ and $m s p-2$ respectively). This corroborates reports from other areas of Central Africa with intense malaria transmission $[22,28]$. In this study, the number of parasite genotypes carried by subjects with symptomatic infections was not influenced by age as shown elsewhere [29]. Irrespective of age, the sensitivity of the technique may not allow for the detection of minor genotypes when the parasite density of disease-inducing strain is high.

However, in contrast with the first report in Brazzaville [5], P. falciparum infection in this symptomatic population shows a significant correlation between parasite density and the number of parasite genotype. This suggests that symptomatic $P$. falciparum infection in this population is associated with the presence and growth of recently inoculated parasite strain(s) to which individuals have either not previously been exposed to or have not fully developed immunity $[13,30]$. This observation in Congolese population is in agreement with the study conducted in Bangui [29] and in Mozambique [31]. The $m s p-1$ and $m s p-2$ genes appeared polymorphic, and both taken together, the relation between parasite density and multiplicity of infection become more pronounced. This finding supposed that in area with high transmission where individuals are exposed to several different clones, disease-inducing strains may have similar growing capacity leading to the increase of their parasite densities. Consequently, with the technique used, the high density may increase the probability to distinguish more clones in the complex infections.

Despite the lack of recent entomological data from Brazzaville, the latest estimation being in 1985 [18], the genetic diversity and multiplicity of infection found in the present study confirm intense malaria transmission in the area. Most likely, fluctuations in alleles were related to variations of the allele ratios in peripheral blood, as observed over several months in the absence of malaria transmission [32]. In this study, blood samples were collected during the rainy season of January to June, when malaria transmission is very intense. All year round studies covering dry and rainy seasons are needed to get the real picture of genetic profiles in this area including a sense on seasonal variations.

With regard to malaria speciation, two isolates had mixed infections of $P$. falciparum $+P$. malariae and $P$. falciparum $+P$. ovale, confirming high sensitivity of molecular tools in detecting sub-microscopic infection.

\section{Conclusion}

The description of malaria parasite population remains a priority malaria research area in the Republic of Congo for a better understanding and evaluation of on-going malaria control interventions. This study was conducted before the implementation of the new policy for the treatment of uncomplicated malaria using ACT. Assessment of the impact of ACT on malaria parasite population and characterization of mutations in $P$. falciparum genes associated with anti-malarial drug resistance would be useful developments.

\section{Acknowledgements}

We are grateful to patients who participated in the study, as well as to mothers and guardians of participating children. We thank the staff of Tenrikyo and Madibou Health Centres for their help in patient recruitment and Chris Vouvoungui for his assistance in analysing the data. We thank Prof. Theonest Mutabingwa for his contribution to the article and for reading and editing the manuscript.

The field study was supported by A20789 project of the Special Programme for Research and Training in Tropical Diseases (TDR), Wold Health Organization, Geneva, Switzerland. This work was funded by CANTAM Network. CANTAM is Central Africa Network on Tuberculosis, HIV/AIDs and Malaria, jointly funded by the European and Developing Countries Clinical Trials Partnership (EDCTP) and the Netherlands-African partnership for capacity development and clinical interventions against poverty-related diseases (NACCAP).

\section{Author details}

'Fondation Congolaise pour la Recherche Médicale, BP 2672 Brazzaville, Republic of Congo. ${ }^{2}$ Faculty of Health Sciences, University Marien Ngouabi, 
BP 2672, Brazzaville, Republic of Congo. ${ }^{3}$ Laboratoire de Pharmacologie, Centre d'Etudes sur les Ressources Végétales, BP 1249 Brazzaville, Republic of Congo. ${ }^{4}$ Centre de Recherche et d'Etude en Sciences Sociales et Humaines, BP 2019 Brazzaville, Republic of Congo. Institute for Tropical Medicine, University of Tübingen, 72074 Tübingen, Germany.

\section{Authors' contributions}

PIM and FVM conducted molecular genetic analysis. The four authors participated in the design of the study, analysis and interpretation of the results, as well as in preparing the manuscript. All authors read and approved the final manuscript.

\section{Conflicts of interests}

The authors declare that they have no competing interests.

Received: 10 June 2011 Accepted: 22 September 2011

Published: 22 September 2011

\section{References}

1. WHO: World malaria report 2010 [http://www.who.int/malaria/ world_malaria_report_2010].

2. Koram KA, Gyan BA: Malaria vaccine development: an endemic country perspective. Hum Vaccin 2010, 6:12-16.

3. Mabiala-Babela JR, Senga P: [Nighttime attendance at the Pediatric Emergency Room of the University Hospital Centre in Brazzaville, Congo](in French). Med Trop 2009, 69:281-285.

4. Nsimba B, Malonga DA, Mouata AM, Louya F, Kiori J, Malanda M, Yocka D, Oko-Ossho J, Ebata-Mongo S, Le Bras J: Efficacy of sulfadoxine/ pyrimethamine in the treatment of uncomplicated Plasmodium falciparum malaria in Republic of Congo. Am J Trop Med Hyg 2004, 70:133-138.

5. Mayengue Pl, Ndounga M, Davy MM, Tandou N, Ntoumi F: In vivo chloroquine resistance and prevalence of the pfcrt codon 76 mutation in Plasmodium falciparum isolates from the Republic of Congo. Acta Trop 2005, 95:219-225.

6. Ndounga M, Mayengue PI, Tahar R, Casimiro PN, Matondo Maya DW, Miakassissa-Mpassi V, Malonga DA, Nsonde-Ntandou F, Mallanda G, Ringwald P, Basco LK, Ntoumi F: Efficacy of sulfadoxine-pyrimethamine, amodiaquine, and sulfadoxine-pyrimethamine-amodiaquine combination for the treatment of uncomplicated falciparum malaria in the urban and suburban areas of Brazzaville (Congo). Acta Trop 2007, 103:163-171.

7. Genton B, Betuela I, Felger I, Al-Yaman F, Anders RF, Saul A, Rare L, Baisor M, Lorry K, Brown GV, Pye D, Irving DO, Smith TA, Beck HP Alpers MP: A recombinant blood-stage malaria vaccine reduces Plasmodium falciparum density and exerts selective pressure on parasite populations in a phase $1-2 b$ trial in Papua New Guinea. J Infect Dis 2002, 185:820-8207.

8. al-Yaman F, Genton B, Reeder JC, Anders RF, Smith T, Alpers MP: Reduced risk of clinical malaria in children infected with multiple clones of Plasmodium falciparum in a highly endemic area: a prospective community study. Trans R Soc Trop Med Hyg 1997, 91:602-605.

9. Farnert A, Rooth I, Snounou G, Bjorkman A: Complexity of Plasmodium falciparum infections is consistent over time and protects against clinical disease in Tanzanian children. J Infect Dis 1999, 179:989-995.

10. Bereczky S, Liljander A, Rooth I, Faraja L, Granath F, Montgomery SM, Farnert A: Multiclonal asymptomatic Plasmodium falciparum infections predict a reduced risk of malaria disease in a Tanzanian population. Microbes Infect 2007, 9:103-110.

11. Mayengue PI, Luty AJ, Rogier C, Baragatti M, Kremsner PG, Ntoumi F: The multiplicity of Plasmodium falciparum infections is associated with acquired immunity to asexual blood stage antigens. Microbes Infect 2009, 11:108-114.

12. Ekala MT, Jouin H, Lekoulou F, Issifou S, Mercereau-Puijalon O, Ntoumi F: Plasmodium falciparum merozoite surface protein 1 (MSP-1): genotyping and humoral responses to allele-specific variants. Acta Trop 2002, 81:33-46.

13. Ntoumi F, Ngoundou-Landji J, Lekoulou F, Luty A, Deloron P, Ringwald P: Site-based study on polymorphism of Plasmodium falciparum msp-1 and msp-2 genes in isolates from two villages in Central Africa. Parassitologia 2000, 42:197-203.
14. Basco LK, Tahar R, Escalante A: Molecular epidemiology of malaria in Cameroon. XVIII. Polymorphisms of the Plasmodium falciparum merozoite surface antigen-2 gene in isolates from symptomatic patients. Am J Trop Med Hyg 2004, 70:238-244.

15. Anong DN, Nkuo-Akenji T, Fru-Cho J, Amambua-Ngwa A, Titanji VP: Genetic diversity of Plasmodium falciparum in Bolifamba, on the slopes of Mount Cameroon: influence of msp1 allelic variants on symptomatic malaria and anaemia. Ann Trop Med Parasitol 2010, 104:25-33.

16. Nsimba B, Jafari-Guemouri S, Malonga DA, Mouata AM, Kiori J, Louya F, Yocka D, Malanda M, Durand R, Le Bras J: Epidemiology of drug-resistant malaria in Republic of Congo: using molecular evidence for monitoring antimalarial drug resistance combined with assessment of antimalarial drug use. Trop Med Int Health 2005, 10:1030-1037.

17. Ndounga M, Tahar R, Basco LK, Casimiro PN, Malonga DA, Ntoumi F: Therapeutic efficacy of sulfadoxine-pyrimethamine and the prevalence of molecular markers of resistance in under 5-year olds in Brazzaville, Congo. Trop Med Int Health 2007, 12:1164-1171.

18. Trape JF, Peelman P, Morault-Peelman B: Criteria for diagnosing clinical malaria among a semi-immune population exposed to intense and perennial transmission. Trans $R$ Soc Trop Med Hyg 1985, 79:435-442.

19. Trape JF, Quinet MC, Nzingoula S, Senga P, Tchichelle F, Carme B, Candito D, Mayanda $H$, Zoulani A: Malaria and urbanization in central Africa: the example of Brazzaville. Part V: Pernicious attacks and mortality. Trans R Soc Trop Med Hyg 1987, 81(Suppl 2):34-42.

20. Culleton RL, Mita T, Ndounga M, Unger H, Cravo PV, Paganotti GM, Takahashi N, Kaneko A, Eto H, Tinto H, Karema C, D'Alessandro U, do Rosario V, Kobayakawa T, Ntoumi F, Carter R, Tanabe K: Failure to detect Plasmodium vivax in West and Central Africa by PCR species typing. Malar J 2008, 7:174.

21. Farnert A, Williams TN, Mwangi TW, Ehlin A, Fegan G, Macharia A, Lowe BS, Montgomery SM, Marsh K: Transmission-dependent tolerance to multiclonalPlasmodium falciparum infection. J Infect Dis 2009, 200:1166-1175

22. Kun JF, Schmidt-Ott RJ, Lehman LG, Lell B, Luckner D, Greve B, Matousek P, Kremsner PG: Merozoite surface antigen 1 and 2 genotypes and rosetting of Plasmodium falciparum in severe and mild malaria in Lambarene, Gabon. Trans R Soc Trop Med Hyg 1998, 92:110-114.

23. Aubouy A, Migot-Nabias F, Deloron P: Polymorphism in two merozoite surface proteins of Plasmodium falciparum isolates from Gabon. Malar $]$ 2003, 2:12.

24. Zwetyenga J, Rogier C, Tall A, Fontenille D, Snounou G, Trape JF, Mercereau-Puijalon O: No influence of age on infection complexity and allelic distribution in Plasmodium falciparum infections in Ndiop, a Senegalese village with seasonal, mesoendemic malaria. Am J Trop Med Hyg 1998, 59:726-735.

25. Sallenave-Sales S, Daubersies P, Mercereau-Puijalon O, Rahimalala L, Contamin H, Druilhe P, Daniel-Ribeiro CT, Ferreira-da-Cruz MF: Plasmodium falciparum: a comparative analysis of the genetic diversity in malariamesoendemic areas of Brazil and Madagascar. Parasitol Res 2000, 86:692-698.

26. Heidari A, Keshavarz H, Rokni MB, Jelinek T: Genetic diversity in merozoite surface protein (msp-1 and msp-2) genes of Plasmodium falciparum in a major endemic region of Iran. Korean J Parasitol 2007, 45:59-63.

27. Peyerl-Hoffmann G, Jelinek T, Kilian A, Kabagambe G, Metzger WG, von Sonnenburg F: Genetic diversity of Plasmodium falciparum and its relationship to parasite density in an area with different malaria endemicities in West Uganda. Trop Med Int Health 2001, 6:607-613.

28. Basco LK, Ringwald P: Molecular epidemiology of malaria in Yaounde, Cameroon. VIII. Multiple Plasmodium falciparum infections in symptomatic patients. Am J Trop Med Hyg 2001, 65:798-803.

29. Dolmazon V, Matsika-Claquin MD, Manirakiza A, Yapou F, Nambot M, Menard D: Genetic diversity and genotype multiplicity of Plasmodium falciparum infections in symptomatic individuals living in Bangui (CAR). Acta Trop 2008, 107:37-42.

30. Contamin H, Fandeur T, Rogier C, Bonnefoy S, Konate L, Trape JF, Mercereau-Puijalon O: Different genetic characteristics of Plasmodium falciparum isolates collected during successive clinical malaria episodes in Senegalese children. Am J Trop Med Hyg 1996, 54:632-643.

31. Mayor A, Saute F, Aponte JJ, Almeda J, Gomez-Olive FX, Dgedge M, Alonso PL: Plasmodium falciparum multiple infections in Mozambique, its 
relation to other malariological indices and to prospective risk of malaria morbidity. Trop Med Int Health 2003, 8:3-11.

32. Zwetyenga J, Rogier C, Spiegel A, Fontenille D, Trape JF, Mercereau-

Puijalon O: A cohort study of Plasmodium falciparum diversity during the dry season in Ndiop, a Senegalese village with seasonal, mesoendemic malaria. Trans R Soc Trop Med Hyg 1999, 93:375-380.

doi:10.1186/1475-2875-10-276

Cite this article as: Mayengue et al: Genetic polymorphism of merozoite surface protein-1 and merozoite surface protein-2 in Plasmodium

falciparum isolates from Brazzaville, Republic of Congo. Malaria Journal 2011 10:276

Submit your next manuscript to BioMed Central and take full advantage of:

- Convenient online submission

- Thorough peer review

- No space constraints or color figure charges

- Immediate publication on acceptance

- Inclusion in PubMed, CAS, Scopus and Google Scholar

- Research which is freely available for redistribution

Submit your manuscript at www.biomedcentral.com/submit 